Supplement of Hydrol. Earth Syst. Sci. Discuss., 12, 2527-2559, 2015

http://www.hydrol-earth-syst-sci-discuss.net/12/2527/2015/

doi:10.5194/hessd-12-2527-2015-supplement

(C) Author(s) 2015. CC Attribution 3.0 License.

(c) (1)

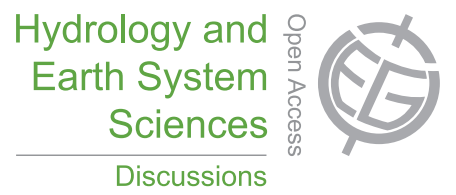

Supplement of

\title{
Characterization of precipitation product errors across the US using multiplicative Triple Collocation
}

S. H. Alemohammad et al.

Correspondence to: S. H. Alemohammad (hamed_al@mit.edu) 
a) Standard Deviation of the RMSE in NEXRAD (logarithmic scale)

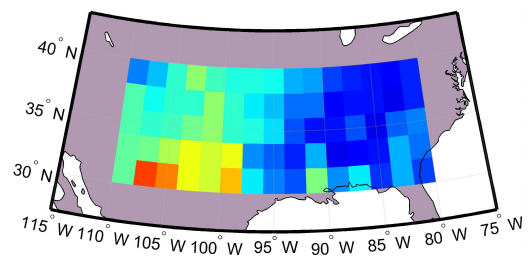

b) Standard Deviation of the RMSE in TRMM (logarithmic scale)

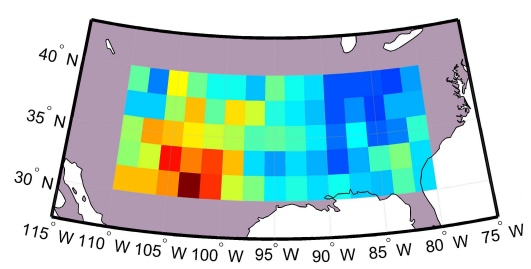

c) Standard Deviation of the RMSE in GPI (logarithmic scale)

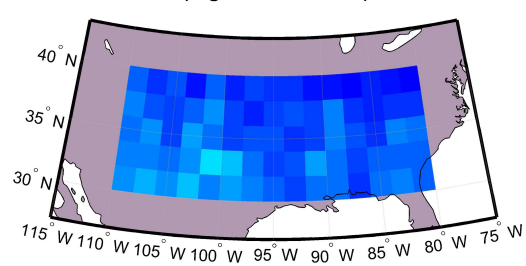

d) Standard Deviation of the RMSE in NEXRAD (logarithmic scale)

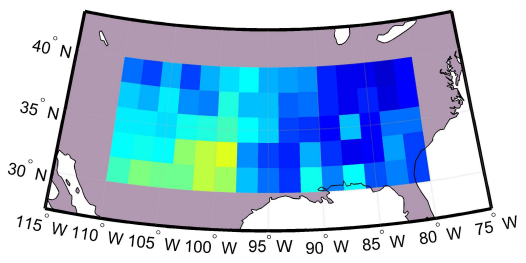

e) Standard Deviation of the RMSE in TRMM (logarithmic scale)

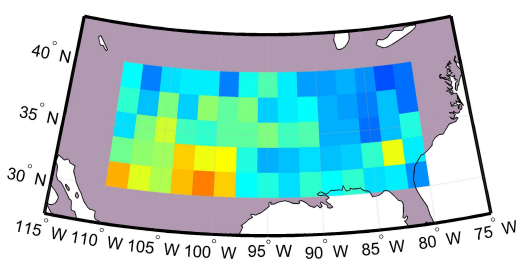

f) Standard Deviation of the RMSE in GPCP (logarithmic scale)

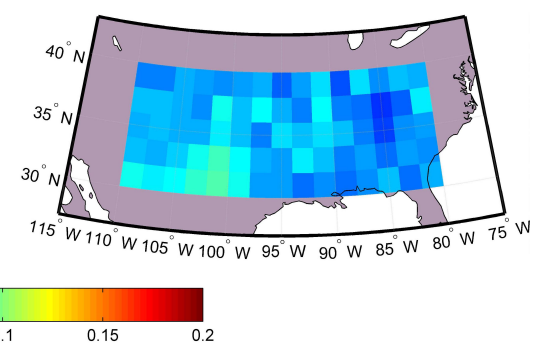

Figure S1: Standard deviation of RMSE estimates of the precipitation rate (derived from bootstrap simulations) in each product. The left column shows the results for triplets in group 1, and the right column shows the results for triplets in group 2. 
a) Standard Deviation of the RMSE in NEXRAD $\mathrm{mm} / \mathrm{day}$

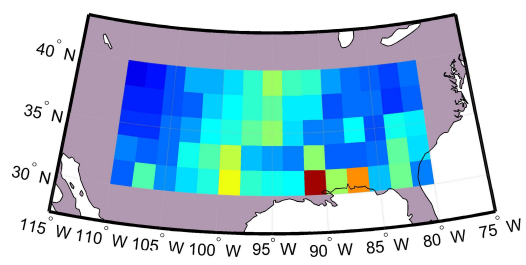

b) Standard Deviation of the RMSE in TRMM $\mathrm{mm} /$ day

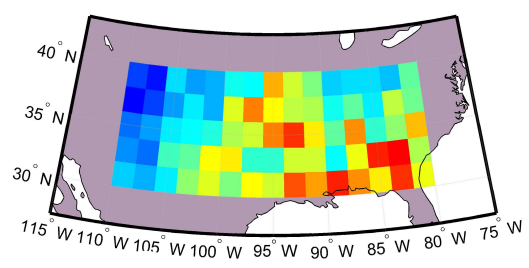

c) Standard Deviation of the RMSE in GPI $\mathrm{mm} /$ day

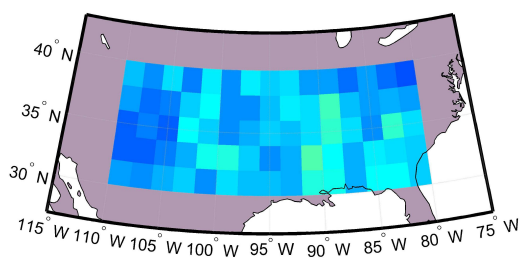

d) Standard Deviation of the RMSE in NEXRAD $\mathrm{mm} / \mathrm{day}$

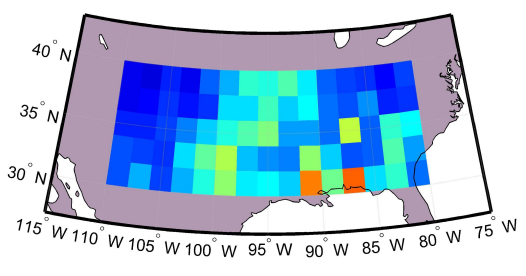

e) Standard Deviation of the RMSE in TRMM $\mathrm{mm} /$ day

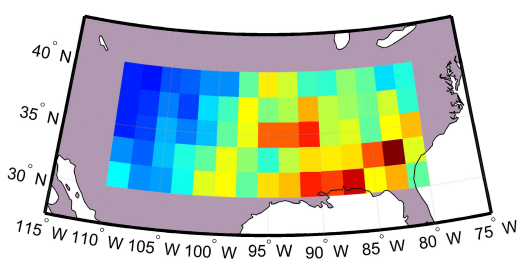

f) Standard Deviation of the RMSE in GPCP $\mathrm{mm} /$ day

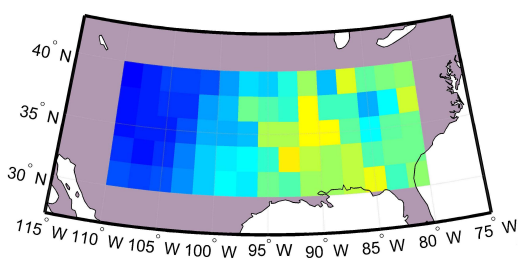

Figure S2: Similar to Figure S1, but in units of mm/day.

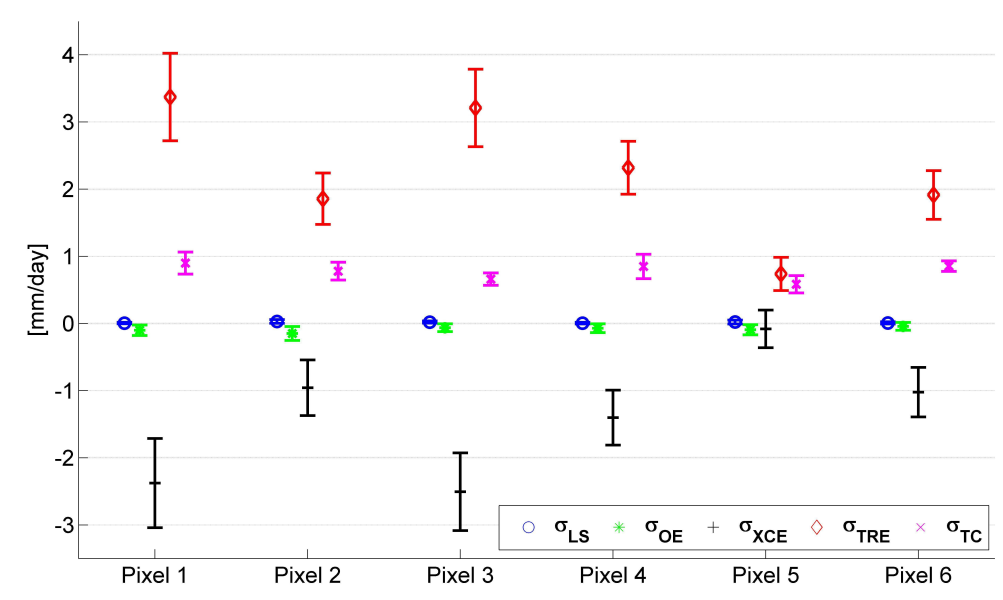

Figure S3: Decomposition of TC estimate of the RMSE of TRMM product across six pixels. 


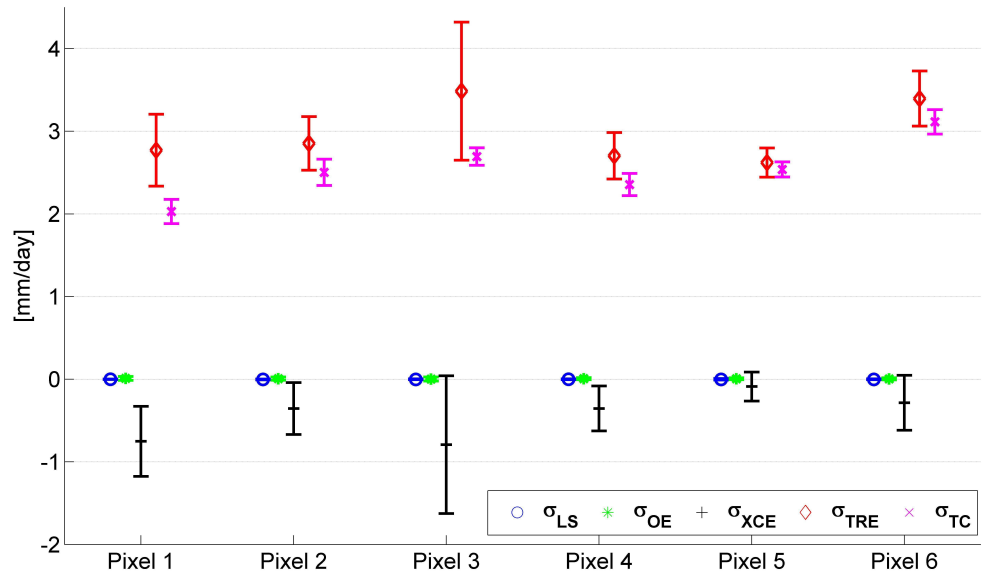

Figure S4: Decomposition of TC estimate of the RMSE of GPCP product across six pixels.

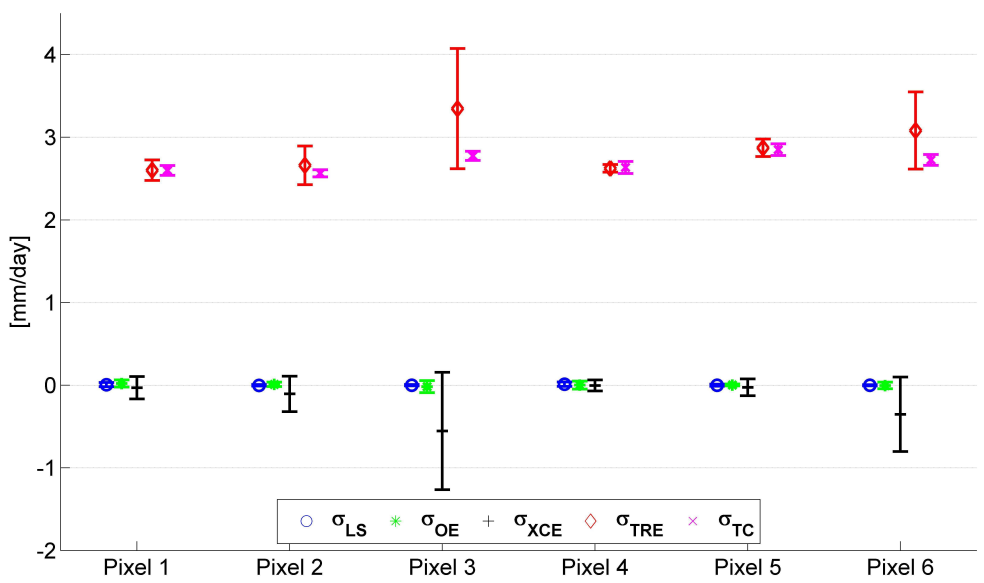

Figure S5: Decomposition of TC estimate of the RMSE of GPI product across six pixels. 